\section{Demand and supply of commercial firearms in the United States}

\section{Jurgen Brauer}

f they are concerned with weapons of war at all, economists who study the topics of conflict, war, peace, and security tend to focus on the production and trade of major conventional arms and of weapons of mass destruction. Small arms rarely capture their attention, or only in the context of the economics of crime, addressed in a different literature. But as the Small Arms Survey in Geneva, Switzerland, has documented, the carrying out of war, and also of violence in postconflict economies that are nominally at "peace", relies far more on small arms, especially firearms, than on major conventional weapons. For both crime (including organized crime) and war, it is important to learn more about small arms, and especially firearms. This includes a characterization of the whole of the firearms industry, not just of the part that is implicated in the misuse and abuse of its products. Yet virtually the only country for which it is possible to obtain relevant data on firearms demand and supply, and on the industrial dynamics of the industry, is the United States. ${ }^{1}$ Learning about the U.S. firearms industry may generate important insights about established or emerging industries elsewhere, such as Brazil, India, Pakistan, and South Africa.

Although the available data are somewhat chancy and contingent, it is possible to establish a proximate record of the annual demand for and supply of firearms in the United States, in actual units rather than in revenue terms. Demand can be estimated with data going back to 1999. Some supply go further back, to 1986. Albeit more problematic, subtracting exports and including imports is possible as well, back to 1989. As it turns out, in the process it is possible to estimate a number for the annual resale of used firearms via federally licensed dealers and to gain a sense of an important metric of competition, namely the domestic market penetration by imports and also of the share of foreign brands in domestic production (i.e., production in the United States by non-U.S. brands). Another benefit of looking at these data is that it becomes possible to examine for its plausibility the standard claim that the stock of firearms in the U.S. amounts to "one gun per person.” This is important because this claim is based on a household survey rather than on market information. ${ }^{2}$

Knowledge of both the quantity of new, domestically produced and retained weapons and of imported firearms would establish a benchmark for annual market supply. Matched against estimates of domestic firearms demand via federally licensed firearms dealers implies that any excess of demand over supply would need to be filled from the resale of used weapons. In round numbers, for the year 2010, firearms demand is estimated at 9.8 million units. On the supply side, firearms imports (both new and used) amounted to 2.9 million units, and domestically produced and retained new firearms (i.e., not exported) ran to about 5.4 million units, for a total supply of 8.3 million weapons. This leaves 1.5 million firearms, a little over fifteen percent of demand that year, to be supplied via the resale of used firearms. Spot interviews with dealers confirm that firearms resale is both common and an appreciably large and profitable part of the retail business.

Prefaced by a discussion on the quality of and restrictions on the data, the following sections address some of the detail and complexities by which to arrive at estimates of units of firearms annually traded in the U.S. and of the total stock to which they may have cumulated.

\section{Data and definitions}

A detailed discussion of data and data sources is available in Brauer (2013). For the time period 1986 to 2010, and based on data derived from the Bureau of Alcohol, Tobacco, Firearms, and Explosives (ATF), one can document the sale of about 98 million new, domestically produced and retained firearms, defined as pistols, revolvers, rifles, and shotguns. In addition, complex data purchased from the U.S. Census Bureau suggest the net import into the United States of another 48 million firearms for the same time period.

While unit sale data can be extracted from ATF paper records, they are known to be incomplete. ${ }^{3}$ For instance, even prominent, large-scale firearms manufacturers at times report production for one year, then the record stops for a year, and then starts up again. Thus, the figure of 98 million firearms reflects underreporting although, in percentage terms, perhaps not by a huge amount. ${ }^{4}$ The ATF defines "production” as that part of production that is released into domestic commerce. Production into inventory is not counted. Even as it is odd, this definition turns out to be useful in that we know the number of firearms released into commerce. This includes sales to law enforcement agencies such as municipal and state police forces, and federal forces such as the Fish and Wildlife Service. Military sales, however, are excluded from the reporting requirement. Likewise, the emphasis on "release into commerce" means that sales from contract manufacturers for other manufacturers are excluded. This is because the law's main concern lies with the tracing of weapons used in crime. Thus, 
the intent is to count only the "street release," so to speak, from manufacturers' stocks to law enforcement agencies, private security firms, retailers, wholesalers, direct endcustomer, or any other nonmilitary customer.

The net import data are harder to understand and to handle. U.S. Customs and Border Protection (Customs) reports data on firearms imports and exports based on tariff schedules published by the U.S. International Trade Commission (USITC). But neither Customs nor the USITC collect all of the raw data. Instead, raw export data is collected by the U.S. Census Bureau (Census), with Customs serving as the reporting agency. Yet if one wishes to purchase data, import or export, this again is handled by Census! Further, the tariff schedules have changed repeatedly over time, and so has the classification of various types of firearms. Unfortunately, Customs does not differentiate between new and used imported weapons nor does it always cleanly separate military from nonmilitary firearms. Inevitably, to use its data, a number of judgment calls have to be made (see Brauer, 2013, for details).

On the demand side, the primary data source comes from the National Instant Criminal Background Check System (NICS), which generates a record maintained by the Federal Bureau of Investigation (FBI). Full monthly data are available as from December 1998. Background checks do not translate one-for-one into retail sales and, again, judgment calls have to be made to estimate firearms demand. For example, from November 1998 to March 2013 NICS recorded over 12.5 million so-called permit checks for the state of Kentucky. For the same state, NICS also recorded an additional 1.2 million handgun checks and 1.8 million long gun checks. A permit refers to a firearms-carrying licence issued by the state of Kentucky. Each month, the state checks whether any of its permit holders may no longer be eligible for firearms possession, e.g., as a result of having committed a felony. Thus, Kentucky conducts continued eligibility checks unrelated to a prospective customer's intent to purchase a firearm from a licensed dealer. Similarly, Utah checks its permits every 90 days against FBI records. Each state maintains its own rules regarding the frequency, if any, with which its issued permits are checked. Thus, to compute firearms demand, the NICS numbers must be adjusted in some way. ${ }^{5}$

Estimating firearms demand and supply

The magnitude of the nonmilitary demand for firearms in the United States can be estimated if one is willing to make two assumptions: First, that all NICS permit checks are routine procedural checks by states against FBI records and are not associated with an intent to purchase a gun; and, second, that all checks by licensed firearms dealers (mostly retailers) against FBI records result in at least one firearms purchase. With these assumptions, the percentage of "in-store" checks out of all NICS checks yields an estimated annual demand.

More specifically, NICS also reports data on "multiple” background checks. This means that a potential customer's record is checked for both a handgun and for a long-gun purchase. Dealer interviews in Georgia, Ohio, and South Carolina suggest that, as a rule of thumb, an average of 1.1 firearms are sold per in-store customer. This will include multiple handguns only (with a single handgun check), multiple long guns only (with a single long-gun check), or a combination of handguns and long guns (with a "multiple” check). As estimates go, one may then add handgun checks, plus long gun checks, plus two multiple checks (for at least one handgun and one long gun), and augment the resulting number by a factor of 1.1, termed here the multiple gun sales factor (MSGF). This may overstate demand, but it is easy to employ a smaller factor such as 1.05. For example, of the 14,409,616 total NICS checks conducted in 2010, a total of 8,700,794 were under the handguns, long guns, and multiple designations. Counting the multiples twice and augmenting the resulting total by 1.1 leads, for 2010, to the aforementioned estimated demand of 9,769,543 million firearms via federally licensed firearms dealers. ${ }^{6}$

If this is a reasonable way to estimate retail demand, then the sources of market supply can now be computed as well, as shown in Table A2. For example, for 2010, ATF-reported domestic unit production amounted to 5,391,311 domestically retained nonmilitary new firearms (column 1). Adding in the 2010 Census-reported import figure of 2,880,333 new and used nonmilitary units (column 2) yields an overall supply of 8,271,644 firearms (column 3). Call this the commercial supply, and recognize that some unknown but probably relatively small portion of this goes to law enforcement agencies and into wholesale and retail inventories. But since retail demand was 9,769,543 (column 4), a difference of at least 1,497,899 firearms (column 5) must have been filled from domestic firearms resales at the dealer level. (The logic of this is roughly analogous to new and used automobile sales via car dealerships and excludes private party and fleet sales. $)^{7}$

From all this, one may then compute-in columns (6) and (7) of Table A2 - the percentage of new and imported firearms (column 6) and the remainder (column 7) which is the percentage of retail market demand filled by domestic firearms resales. Averaged over the 12 years of data, the split is roughly 75/25. Interestingly, in a small number of nonrandom, spot interviews with a variety of retailers in Georgia, Ohio, and South Carolina (pawn shops, specialist firearms retailers, a shooting range with retail segment), the (unprompted) dealers routinely referred to a number of around 25 percent as their used firearms unit sales out of overall firearms unit sales and, in 2011 when the interviews were conducted, they unanimously bemoaned the shortage of used firearms available for resale. (This is because the sales margin on used firearms is much higher than that on the sale of new firearms. ${ }^{8}$ )

Regarding the plausibility of the "one gun per person" survey-based number, for the years 1986 to 2010, the combined supply data of ATF and Census suggests total commercial supplies of about 98 million domestically produced and retained firearms, plus about 48 million imported firearms, for a total of 146 million firearms over this 25-year period. Adding "miscellaneous" firearms and firearms for the U.S. military brings the total to little more than 150 million. ${ }^{9}$ Attrition rates are not known: Theft 
merely recycles a weapon and military and police forces resell older weapons to help finance the procuring of new ones. For true attrition from the existing stock, one would need to know the number of weapons destroyed or damaged beyond repair, irretrievably discarded, or otherwise rendered unusable. No one knows this number. But even if one assumes a cumulative attrition rate of ten percent (older weapons at higher rates than newer ones), a total flow of 150 million firearms from 1986 to 2010 would result in a 2010 stock of 135 million firearms. Since firearms are long-lasting, large numbers of firearms that entered commerce before 1986 would still be in stock as well. If one could extend the exercise of harvesting ATF and Customs data by another 25 years, back to 1961, the "one gun per person" then appears quite plausible.

\section{Domestically produced versus imported firearms}

ATF data on new, nonmilitary, domestically retained firearms entering commerce and the import data from Census can also be used to compute the changing composition of commercial supplies (domestic versus foreign origin). The findings are shown in Figure 1. Due to substantial tariff schedule reclassifications of firearms imports, the Census data for (mostly) nonmilitary imports are displayed only as from 1989 (and, for comparative convenience, so are the ATF data). In Figure 1, then, the solid bottom (green) line shows the import numbers, on the left-hand side (LHS) scale, per 100,000 people. These rose from 489 firearms per 100,000 people in 1989 to almost twice as many, namely 931 imported firearms per 100,000 people in 2010. In contrast, supplies from domestic sources (the solid blue line, 2nd from the bottom) stayed fairly constant, at 1,769 firearms per 100,000 in 1989 and 1,743 in 2010. Unlike imported firearms, domestically supplied arms show a strong decline for much of the 1990s and through to about 2005 before rising again to their earlier level. The solid top (red) line adds the numbers for domestic and imported firearms. Starting in 1989 at 2,272 units per 100,000 people, annual additions to the firearms stock declined precipitously through the mid-1990s, then flattened out for about ten years, before rising rapidly to 2,674 firearms per 100,000 people in 2010.

Importantly, however, the composition of the origin of firearms has changed markedly. Using the right-hand side (RHS) scale, the purple dashed line in Figure 1 shows that in 1989 U.S.-based manufacturers provided nearly 80 percent of the firearms. During the 1990s, this percentage fell steadily to around 60 percent, a level that then prevailed throughout most of the 2000s. This does not tell the whole story of market penetration by foreign brands, though. While ATF records do not contain ownership information, the major non-U.S. brands are of course well known. In the pistol segment of the market they captured 21.9 percent of the top-20 sellers' market share in 2010. (The top-20 themselves accounted for 92.3 percent of the total pistol market.) The foreign brands among the top-20 pistol makers were Sig Sauer (Germany; 266,316 pistols), Beretta (Italy; 133,397), Taurus (Brazil; 128,160), Glock (Austria; 31,395), and Chiappa (Italy; 26,278), selling a total of well over half a

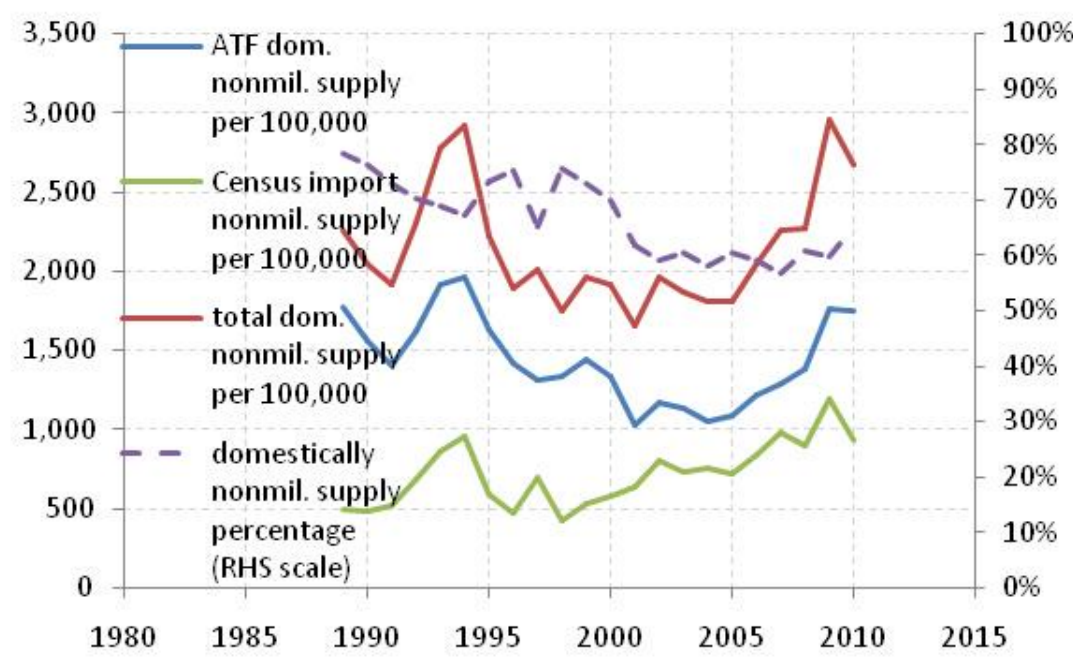

Figure 1: The share of imported firearms, 1989-2010 (nonmilitary firearms, in units per 100,000 people).

Source: Brauer, 2013.

million pistols in 2010 alone. For comparison, ten years earlier, in 2001, only Beretta $(58,151)$ and Taurus $(7,114)$ were ranked in the top-20 list of pistol makers.

Foreign-brand penetration is not evident in the revolver segment (only Chiappa shows up in the top-20) or the shotgun segment (only Beretta), and the rifle segment is only beginning to be affected (Sig Sauer and FN Herstal, Belgium). Nevertheless, it is clear that a fundamental change on the supply side of the U.S. firearms market has occurred. Figure 1 shows massive, and massively increasing, firearms imports, and a closer look at the firearms market segments shows that even among "domestic," i.e., U.S.-based producers, foreign brands have gained much market share. ${ }^{10}$ These observations would appear to be restricted to the pistol market in particular, but the trade press suggests that U.S. rifle and shotgun manufacturers increasingly source parts from abroad, e.g., from Mexico, Russia, and Turkey.

\section{Conclusion}

The findings reported in this article suggest that United States firearms producers have experienced import pressures not unlike those that have affected other branches of U.S. manufacturing, such as commercial shipbuilding, automobile manufacturing, consumer electronics, and household furniture. From the point of view of industrial economics, and in marked contrast to major conventional arms, the U.S. firearms industry likely functions much like other branches of U.S. commercial manufacturing. 
This probably implies, for instance, that any firearms import restrictions would be countered by resurgent domestic manufacture, even if at possibly increased end-user prices. Similarly, if restrictions were placed on production within the United States, this likely would lead to displacement of manufacturing facilities from "gununfriendly” to "gun-friendly” states or to an even greater reliance on firearms imports.

In addition to the rising market share of imports and of foreign-brands in domestic production, a completely new aspect of firearms research reported here concerns the share of firearms resales in total firearms sales. A rough estimate suggests that around one-quarter of dealer-level firearms sales may stem from used firearms. The research further suggests that the notion of a firearms stock of an average of "one gun per person" in the United States is likely a reasonable approximation.

The contours on firearms quantities having been established, further research will need to generate knowledge of wholesale or retail prices and better understand the nature of competition in the firearms market. For the whole of the 1986 to 2010 time period, Brauer (2013) traced well over 2,000 U.S.-based firearms manufacturers but showed that just three brands-Ruger, Remington, and Smith \& Wesson-supplied over 40 percent of the market. Even so, in all market segments entry and exit can readily be observed and, as pointed out for the case of foreign-brand penetration in the pistol segment of the market, successful entry into the list of top-20 sellers has been possible. All this speaks to the roles of technology and product innovation, marketing, and brand reputation effects, certainly topics to which economists have much to contribute. Additionally, since location data by state, city, and street is available from the ATF for all U.S.-based firearms manufacturers, it should be possible to learn about the economics of agglomeration in the firearms market or if changes in firearms legislation affect manufacturers' location or relocation decisions.

Finally, most firearms manufacturers are privately-held firms. But shares for a very few are, or have at times been, publicly traded. For such firms, substantial financial records can be obtained from the U.S. Securities and Exchange Commission (SEC). Among other things, one would learn much about costs, including R\&D and labor costs and, given the apparently competitive nature of the market, one probably could draw reasonable inferences about the market at large.

Altogether, it appears that much can in fact be learned about the industry per se, rather than only about those aspects having to do with the misuse or abuse of its products. And to understand the development and dynamics of the firearms industry in one market (the United States) could then conceivably assist in understanding the development of dynamics of the firearms market elsewhere, such as in Brazil, India, Pakistan, or South Africa.

\section{Notes}

Jurgen Brauer is Professor of Economics, Hull College of Business, Georgia Regents University, Augusta, GA, USA. He may be reached at < jbrauer@gru.edu>.
1. Small Arms Survey: See, e.g., the annual yearbooks, published since 2001. Misuse and abuse: I distinguish among firearms use, misuse, and abuse. Misuse includes, e.g., accidental shootings or suicides; abuse includes criminal use especially, but not only, homicide. Use includes collecting, target shooting, hunting, and legitimate selfdefense.

2. One gun per person: Hepburn, et al. (2007) report the number of firearms in individual possession in 2004 as 283 million. (At the time, the U.S. population was about 293 million, hence the "one gun per person" shorthand.) This estimate is based on a nationally representative sample, conducted in spring 2004 by four researchers at the Department of Health Policy and Management, Harvard School of Public Health, of 2,770 adults of age 18 and older. To this must be added stocks of law enforcement and similar agencies. Earlier estimates, discussed in Hepburn, et al. (2007), reported stocks of 192 million firearms in 1994 and 258 million firearms in 1999, respectively. Quite a bit of controversy surrounds these and other survey-based estimates, such as those conducted by the General Social Survey, Gallup, Pew Research, ABC News/Washington Post, and by academic researchers. See the summative discussion and numbers in Bialik (2013a; 2013b). See also Legault and Lizotte (2009).

3. ATF publishes its data in the Annual Firearms Manufacturers and Export Report (AFMER), see http://www.atf.gov/statistics/index.html [accessed 21 April 2013]. At the time of writing, AFMER was available for 1998 to 2010. Data back to 1986 were obtained via a Freedom of Information Act (FIA) request.

4. The ATF attempts to audit all manufacturers' records once every five years. Any omissions or errors are then said to be reflected in updated AFMER's so that AFMER more than five years old are deemed correct by the ATF.

\section{Table A1 lists the monthly NICS totals for November 1998 to December 2010.}

6. The National Shooting Sports Foundation (NSSF), an industry group, also adjusts the monthly NICS numbers. At less five percentage points, the difference to the adjustment used in this article is not large.

7. Whereas the estimated retail demand necessarily excludes figures for the demand stemming from law enforcement agencies, the total supply of 8,271,644 must be reduced by the unknown diversion to law enforcement ("fleet" sales) and inventories thus reducing the retail supply. Hence, the gap between retail demand and retail supply becomes wider, so that the resale of used firearms will be larger than the estimated 1.5 million units reported in the text. The figure of 1.5 million would be the estimated minimum of firearms resales at the dealer level. 
8. Sales margins: See NSSF (2010, p. 21). For the year 2009, NSSF retail survey respondents $(n=228)$ reported an average sales margin of $19 \%$ for new firearms (handguns, rifles, and shotguns). In contrast, the average sales margin was 29\% for used firearms $(n=211)$. Over 20 percent of gross sales derived from the sale of used firearms $(n=245)$.

9. Adding in "miscellaneous" commercial firearms brings the total from 98.2 to 99.3 million units. The flow of firearms to the military is relatively small. For a generous approximation, assume an average of two firearms per person and an average force level of 1.5 million personnel and also assume a ten-year firearms replacement cycle (a factor of 2.5 over 25 years). The total would then come to 7.5 million firearms. Half that, or say four million, might be a more realistic number.

10. Foreign- and, especially, European-brand firearms are increasingly used in crime as well which, as Nicholas Marsh of the Peace Research Institute, Oslo (PRIO) suggests, should make Europeans less smug about high levels of U.S. firearms crime. See http://www.dw.de/european-arms-money-fuel-us-gun-addiction/a-16540687 [accessed 18 April 2013].

\section{References}

Bialik, C. 2013a. "Gun Counts Can Be Hit-or-Miss.” The Wall Street Journal. 22 March 2013. See http://online.wsj.com/article/SB100014241278873241035045 78374692383804654.html [accessed 18 April 2013].

Bialik, C. 2013b. “Guns Present Polling Conundrum.” The Wall Street Journal Blogs. 22 March 2013. See http://blogs.wsj.com/numbersguy/guns-present-pollingconundrum-1223/ [accessed 18 April 2013].

Brauer, J. 2013. “The US Firearms Industry: Production and Supply.” Working Paper 14. Geneva: Small Arms Survey.

Hepburn, L., M. Miller, D. Azrael, and D. Hemenway. 2007. "The US gun stock: results from the 2004 national firearms survey.” Injury Prevention. Vol. 13, No. 1 (February), pp. 15-19. See http://www.ncbi.nlm.nih.gov/pmc/articles/

PMC2610545/ [accessed 18 April 2013.]

Legault, R.L., A.J. Lizotte. 2009. "Caught in the Crossfire: Legal and Illegal Gun Ownership in America,” pp. 469-492 in M.D. Krohn, A.J. Lizotte, and G. Penly Hall, eds. Handbook on Crime and Deviance. Dordrecht, Heidelberg, London, New York: Springer.

[NSSF] National Shooting Sports Foundation. 2010. 2010 Firearms Retailer Survey. Prepared by Southwick Associates (Fernandina Beach, FL) for the NSSF. 
The Economics of Peace and Security Journal, ISSN 1749-852X

(C) www.epsjournal.org.uk - Vol. 8, No. 1 (2013)

Table A 1: Total NICS background checks by month, November 1998 to December 2010

\begin{tabular}{|c|c|c|c|c|c|c|c|c|c|c|c|c|c|}
\hline & Jan. & Feb. & Mar. & Apr. & May & June & July & Aug. & Sept. & Oct. & Nov. & Dec. & Total/year \\
\hline 1998 & & & & & & & & & & & 21,196 & 871,644 & 892,840 \\
\hline 1999 & 591,355 & 696,323 & 753,083 & 646,712 & 576,272 & 569,493 & 589,476 & 703,394 & 808,627 & 945,701 & $1,004,333$ & $1,253,354$ & $9,138,123$ \\
\hline 200 & 639,972 & 707,070 & 736,543 & 617,689 & 538,648 & 550,561 & 542,520 & 682,501 & 782,087 & 845,886 & 898,598 & $1,000,962$ & $8,543,037$ \\
\hline 2001 & 640,528 & 675,156 & 729,532 & 594,723 & 543,501 & 540,491 & 539,498 & 707,288 & 864,038 & $1,029,691$ & 983,186 & $1,062,559$ & $8,910,191$ \\
\hline 2002 & 665,803 & 694,668 & 714,665 & 627,745 & 569,247 & 518,351 & 535,594 & 693,139 & 724,123 & 849,281 & 887,647 & 974,059 & $8,454,322$ \\
\hline 2003 & 653,751 & 708,281 & 736,864 & 622,832 & 567,436 & 529,334 & 533,289 & 683,517 & 738,371 & 856,863 & 842,932 & $1,008,118$ & $8,481,588$ \\
\hline 2002 & 695,000 & 723,654 & 738,298 & 642,589 & 542,456 & 546,847 & 561,773 & 666,598 & 740,260 & 865,741 & 890,754 & $1,073,701$ & $8,687,671$ \\
\hline 2005 & 685,811 & 743,070 & 768,290 & 658,954 & 557,058 & 555,560 & 561,358 & 687,012 & 791,353 & 852,478 & 927,419 & $1,164,582$ & $8,952,945$ \\
\hline 2006 & 775,518 & 820,679 & 845,219 & 700,373 & 626,270 & 616,097 & 631,156 & 833,070 & 919,487 & 970,030 & $1,045,194$ & $1,253,840$ & $10,036,933$ \\
\hline 2007 & 894,608 & 914,954 & 975,806 & 840,271 & 803,051 & 792,943 & 757,884 & 917,358 & 944,889 & $1,025,123$ & $1,079,923$ & $1,230,525$ & $11,177,335$ \\
\hline & 942,556 & ,021,130 & $1,040,863$ & 940,961 & 886,183 & 819,891 & 891,224 & 956,872 & 973,003 & $1,183,279$ & $1,529,635$ & $1,523,426$ & $12,709,023$ \\
\hline 2( & ,213,885 & 59,078 & $1,345,096$ & $1,225,980$ & $1,023,102$ & 968,145 & 966,162 & $1,074,757$ & $1,093,230$ & 1,233,982 & $1,223,252$ & $1,407,155$ & $14,033,824$ \\
\hline 2010 & $1,119,229$ & $1,243,211$ & $1,300,100$ & $1,233,761$ & $1,016,876$ & $1,005,876$ & $1,069,792$ & $1,089,374$ & $1,145,798$ & $1,368,184$ & $1,296,223$ & $1,521,192$ & $14,409,616$ \\
\hline Total & & & & & & & & & & & & & $124,427,448$ \\
\hline
\end{tabular}

Source: http://www.fbi.gov/about-us/cjis/nics [accessed 17 April 2013]

Table A2: Approximate demand and supply of U.S. commercial firearms, 1999-2010

$\begin{array}{rlllrrrr}\text { Year } & \text { (1) } & \text { (2) } & \text { (3) } & \text { (4) } & \text { (5) } & \text { (6) } & (7) \\ 1999 & 4,007,910 & 1,482,990 & 5,490,900 & 8,757,843 & 3,266,943 & 62.7 & 37.3 \\ 2000 & 3,763,345 & 1,625,996 & 5,389,341 & 7,879,752 & 2,490,411 & 68.4 & 31.6 \\ 2001 & 2,907,580 & 1,807,001 & 4,714,581 & 8,035,308 & 3,320,727 & 58.7 & 41.3 \\ 2002 & 3,345,195 & 2,308,853 & 5,654,048 & 7,084,617 & 1,430,569 & 79.8 & 20.2 \\ 2003 & 3,277,426 & 2,132,623 & 5,410,049 & 7,075,868 & 1,665,819 & 76.5 & 23.5 \\ 2004 & 3,079,517 & 2,217,721 & 5,297,238 & 7,371,405 & 2,074,167 & 71.9 & 28.1 \\ 2005 & 3,218,315 & 2,117,859 & 5,336,174 & 7,750,274 & 2,414,100 & 68.9 & 31.1 \\ 2006 & 3,614,452 & 2,497,273 & 6,111,725 & 8,240,265 & 2,128,540 & 74.2 & 25.8 \\ 2007 & 3,867,152 & 2,948,421 & 6,815,573 & 8,640,641 & 1,825,068 & 78.9 & 21.1 \\ 2008 & 4,195,873 & 2,713,303 & 6,909,176 & 9,473,556 & 2,564,380 & 72.9 & 27.1 \\ 2009 & 5,417,003 & 3,641,952 & 9,058,955 & 10,053,577 & 994,622 & 90.1 & 9.9 \\ 2010 & 5,391,311 & 2,880,333 & 8,271,644 & 9,769,543 & 1,497,899 & 84.7 & 15.3\end{array}$

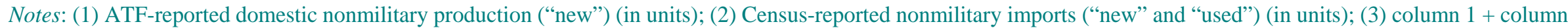

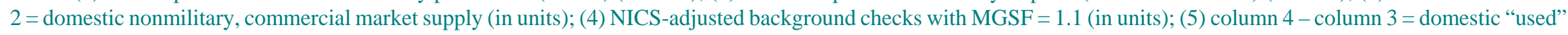
gun purchases (in units); (6) new + imported gun purchases (\%); (7) domestic used gun purchases (\%).

Source: Source: Author's calculations from ATF (AFMER), USCB, and FBI data for the relevant years. 